Philippe Morimont

Bernard Lambermont Valérie Gaspard Jean-Olivier Defraigne

\section{Molding thrombus of an ECMO cannula floating in the right atrium}

Received: 25 March 2015

Accepted: 25 March 2015

(C) Springer-Verlag Berlin Heidelberg and ESICM 2015

Electronic supplementary material The online version of this article (doi:10.1007/s00134-015-3779-0) contains supplementary material, which is available to authorized users.

P. Morimont $(\bowtie) \cdot$ B. Lambermont

Medical Intensive Care Unit, Department of Medicine, University

Hospital of Liege, 4000 Liege, Belgium

e-mail: ph.morimont@chu.ulg.ac.be

Tel.: +32-4-3667312

V. Gaspard

Department of Anesthesiology, University Hospital of Liege, Liege, Belgium

J.-O. Defraigne

Department of Cardiothoracic Surgery, University Hospital of Liege, Liege, Belgium
A 23-year-old man was referred to us for veno-arterial extracorporeal membrane oxygenation (VA ECMO) support as a bridge to heart transplantation. He presented with refractory cardiogenic shock resulting from toxic cardiomyopathy secondary to recreational cocaine use. After a waiting period of 3 weeks with femoro-femoral VA ECMO support without major complications, he was transplanted. The peripheral VA ECMO was left in place for $24 \mathrm{~h}$ following transplantation and removed after a gradual weaning process under adequate anticoagulation. Echocardiography performed $12 \mathrm{~h}$ later revealed a long tubular structure, about $20 \mathrm{~cm}$ long, which was anchored at the middle part of the posterior wall of the right atrium and passed throughout the tricuspid valve at each diastole (Fig. 1a-c; Electronic Supplementary Material videos S1, S2). The patient was taken immediately to the operating theater for removal of this thrombus which appeared to be a perfect mold of the inflow cannula (Fig. 1d). The outcome was excellent. This case illustrates how cannula
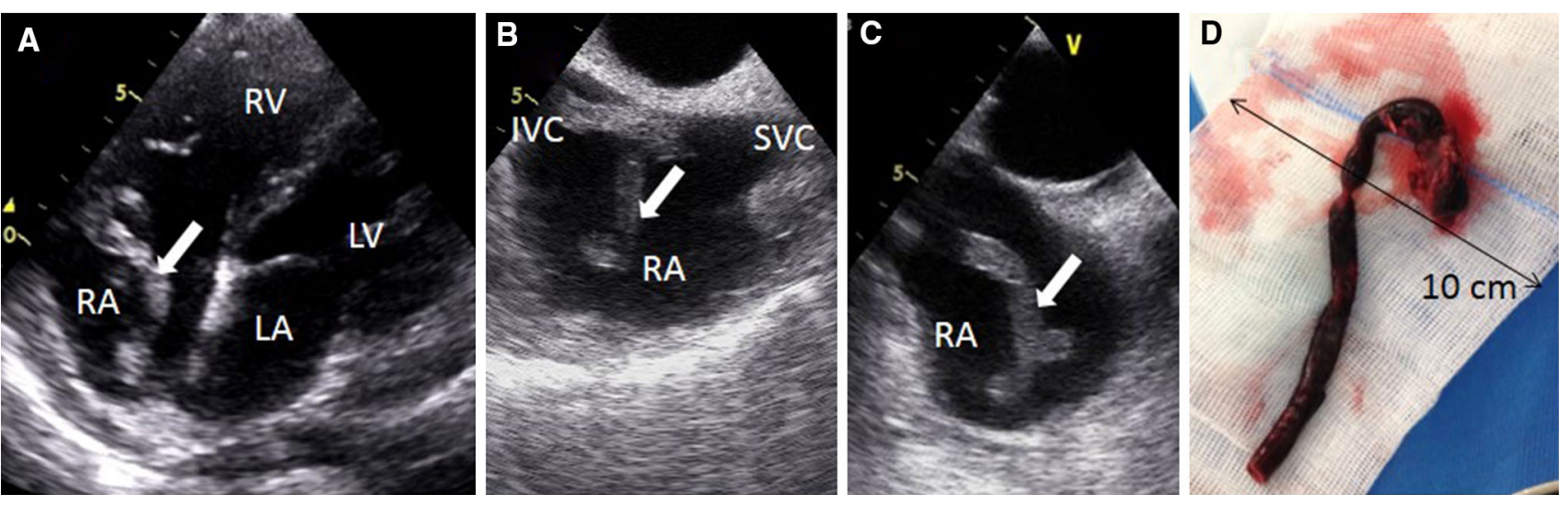

Fig. 1 Echocardiography after cannula removal showing the tubular thrombus. a Transthoracic apical 4-chamber view, b, c transoesophageal bicaval (b) and right atrial (c) views, d postoperative picture of the thrombus corresponding to a mold of the

inflow cannula. $R V$ Right ventricle, $R A$ right atrium, $L V$ left ventricle, $L A$ left atrium, $S V C$ superior vena cava, $I V C$ inferior vena cava 
thrombus may appear during the weaning process, in Echocardiographic control should be performed systemparticular during the clamping period. Cannulas should be atically during weaning process and removal of cannulas. flushed with normal saline before clamping when the thromboembolism risk has been preliminarily eliminated. Conflicts of interest None. 